\title{
Outbreak of Cyclosporiasis in Korean Travelers Returning from Nepal
}

\author{
Da-Won Ma, Myoung-Ro Lee, Bora Ku, Shin-Hyeong Cho, Sang-Eun Lee* (i) \\ Division of Vectors \& Parasitic Diseases, Korea Disease Control and Prevention Agency, Cheongju 28159, Korea
}

\begin{abstract}
Cyclospora cayetanensis is an apicomplexan protozoan and is one of the most common pathogens causing chronic diarrhea worldwide. Eight stool samples with diarrheal symptom out of 18 Korean residents who traveled to Nepal were obtained, and examined for 25 enteropathogens including 16 bacterial species, 5 viral species, and 4 protozoans in stool samples as causative agents of water-borne and food-borne disease. Only C. cayetanensis was detected by nested PCR, and 3 PCR-positive samples were sequenced to confirm species identification. However, the oocysts of C. cayetanensis in fecal samples could not be detected by direct microscopy of the stained sample. As far as we know, this is the first report of a group infection with $C$. cayetanensis from a traveler visiting Nepal, and the second report of a traveler's diarrhea by C. cayetanensis imported in Korea.
\end{abstract}

Key words: Cyclospora cayetanensis, traveler's diarrhea, protozoa, PCR, Korea

Gut pathogens, including parasites, are the leading cause of infections leading to enteric illness, and the predominant pathogenic organisms may vary temporally and spatially [1]. Cyclospora cayetanensis among these diverse gut pathogens has emerged as one of the most common apicomplexan protozoan causing chronic diarrhea illness worldwide [2]. C. cayetanensis initially known as coccidian-like body, large Cryptosporidium or small isospora-like protozoan. Like other diarrhea-causing pathogens, C. cayetanensis mainly causes acute watery diarrhea and abdominal pain, nausea and low grade of fever. Species of genus Cyclospora is known as host-specific. The human is known to only hosts of $C$. cayetanensis and become infected by ingesting food or water contaminated by oocysts. Moreover, this pathogen has been associated with cases of international traveler's diarrhea globally [3]. Epidemiologically, it is seasonal world wide, even though there are regional changes. Its main diagnostic methods were oocyst detection with modified acidfast staining by microscopy and molecular detection by PCR in fecal samples [4]. Moreover, also, this pathogen has been associated with cases of international traveler's diarrhea globally $[5,6]$.

\footnotetext{
- Received 24 April 2020, revised 10 September 2020, accepted 15 September 2020. *Corresponding author (ondalg|@korea.kr) (c) 2020, Korean Society for Parasitology and Tropical Medicine This is an Open Access article distributed under the terms of the Creative Commons Attribution Non-Commercial License (https://creativecommons.org/licenses/by-nc/4.0) which permits unrestricted non-commercial use, distribution, and reproduction in any medium, provided the original work is properly cited.
}

In recent years, this pathogen has been increasingly observed both in developed countries, such as the United States of America, United Kingdom and Canada [7-9], and in developing countries such as India, Nepal, Papua New Guinea, Vietnam, and Indonesia [7,10-14]. Especially, Nepal is one of the South-Asia countries with highly prevalent of intestinal pathogens and showed a higher prevalence of $C$. cayetanensis in drinking water, sewage water, green leafy vegetables, and school children [15-18]. In Korea, only one imported case with cyclosporiasis was reported from an individual infected after visiting Indonesia [19]. We report here the first case of a group infection with C. cayetanensis among Korean travelers returning from Nepal.

Eighteen Korean residents traveled to Nepal for 9 days (April $1-9,2013)$ together through a tour company. Among them, one person who had continuous diarrhea after returning to Korea visited the Community Health Care Center (CHCC) in Sokcho-si, Gangwon-do, Korea. Her chief clinical complaint was chronic watery diarrhea continuing for 3-5 days with a frequency of 1-2 times a day. Through a clinical consultation at CHCC, a diarrheal event with her colleagues who traveled to Nepal recognized, and all of them were examined to epidemiological investigation as an outbreak of water-borne or foodborne disease. After the consultation, its outbreak of diarrhea was reported through the surveillance system for mass food poisoning in Korea Centers for Disease Control and Prevention (KCDC). 
After consultation of the first patient, additional stool samples were collected from her 7 colleagues with consent to epidemiological investigation about 5 days later. According to Guideline for Water-borne and Foodborne Diseases Control in KCDC, a total of 25 species pathogens, 16 bacterial species including Vibrio cholerae, Shigella spp, and pathogenic Escherichia coli, 5 viral species including Rotavirus and Norovirus, and 4 protozoans including Giardia lamblia and Cryptosporidium parvum/hominis, were targeted to examine [20]. The bacterial and viral pathogens were tested by the Public Health and Environment Research Institute (PHERI) in Gangwon-do, and protozoans were examined by the Division of Vectors \& Parasitic Diseases (DVPD), KCDC. To detect water-borne pathogens from the stool samples, all stool samples were smeared on glass slides using the formalin-ether method and stained with modified acid-fast staining (MAFS) under microscopic observation for 3 times repeating the examination. Moreover, molecular detection method, nested PCR was performed for 4 protozoan parasite detection (Cryptosporidium parrum/hominis, Giardia lamblia, Entamoeba histolytica, C. cayetanensis). As a result, C. cayetanensis was identified in 3 out of 8 patients through nested PCR and sequencing analysis.

In Korea, the first case of cyclosporiasis causing traveler's diarrhea was reported in 2003 in a patient who had traveled to Indonesia [19]. Similarly, in the present case, 8 of the 18 Korean travelers who visited Nepal together on April 1-9, 2013, had enteric symptoms, including diarrhea, upon their return to Korea, and a total of 8 stool samples from 8 patients were collected around April 20. Both Indonesia and Nepal are known as endemic regions of $C$. cayetanensis, so individuals may be suspected of being unknowingly exposed to C. cayetanensis while traveling. Common symptoms of $C$. cayetanensis infection are characterized by anorexia, watery diarrhea, fatigue, and low-grade fever; however, it can also be asymptomatic [4]. These and previous cases were similar in that they had diarrhea for 3 to 5 days after returning home as major clinical symptoms. They have all clinical symptoms like diarrhea $(75 \%, 6 / 8)$, emesis $(12.5 \%, 1 / 8)$, fever $(12.5 \%, 1 / 8)$, and stomachache $(25 \%, 2 / 8)$ (Table 1). However most of them did not visit a local hospital except 1 patient who visit a clinic at one time.

At the present investigation, any virus and bacterial microbes were not detected in all fecal samples through laboratory testing, whereas only the specific gene for $C$. cayetanensis was detected in 3 out of the 8 samples by nested PCR, showing a 294-bp fragment amplification of the 18S rRNA gene of the pathogen, F3E (5'-CCTTCCGCGCTTCGCTGCGT- $3^{\prime}$ ) and R4B (5'-CGTCTTCAAACCCCCTACTG-3'), and the annealing temperature was $60^{\circ} \mathrm{C}$, following PCR procedure to the previsous report [19] (Fig. 1). Using the sequencing data, phylogenetic trees were constructed using the CLUSTAL W multiple sequence alignment computer program (Histon, Cambridgeshire, UK) and the Molecular Evolutionary Genetics Analysis (MEGA) program; the robustness of groupings was assessed using 1,000 bootstrap replicates of the data. In comparative sequencing analysis of 3 PCR positive cases, all sequences showed 98\% genetic identity with C. cayetanensis $18 \mathrm{~S}$ rRNA and showed high similarity to sequences derived from 2 case individuals in Nepal (Accession No. U40261, AF111183) (Fig. 2) [21]. However, unfortunately, it could not be detected any oocysts of $C$. cayetanensis in all MAFS-stained samples by direct microscopy examination.

In the first outbreak of cyclosporiasis reported in Korea, the early stage stool samples isolated from patients showing diarrheal symptoms were collected in hospital returning to Korea; thus, oocysts of $C$. cayetanensis could be possible to more readily

Table 1. Clinical symptoms of 8 Korean travelers upon their return from Nepal

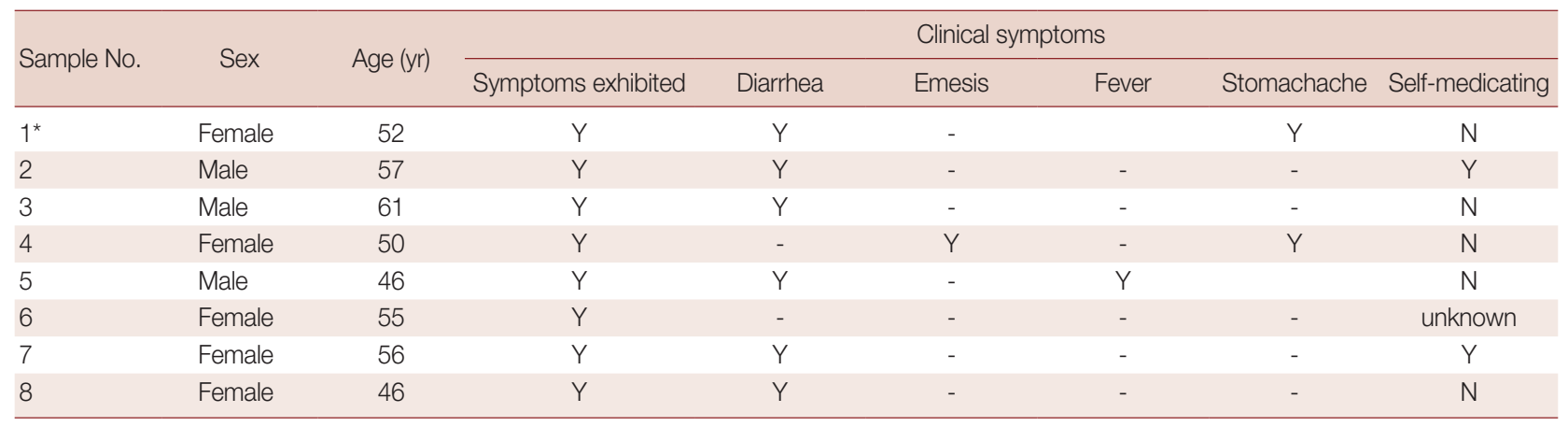

*1 patient only visited a local clinic; Y, yes; N, no. 


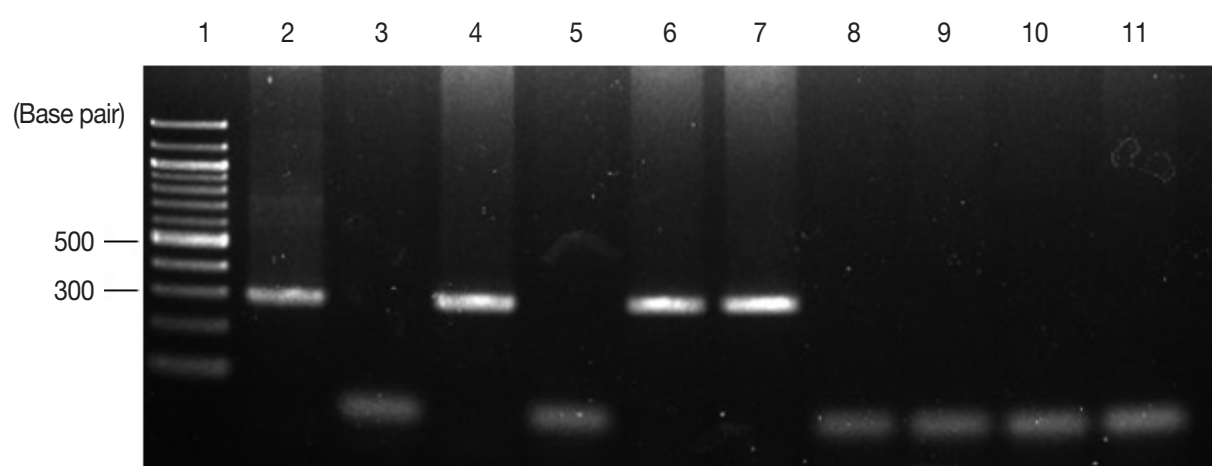

Fig. 1. Detection of Cyclospora cayetanensis by nested PCR of stool samples obtained from 8 patients. To identify C. cayetanensis in feces, nested PCR was performed to amplify a fragment of the 18S rRNA gene of C. cayetanensis, and 294-base pair amplicons were observed by electrophoresis. Lane 1, 100-bp DNA ladder; Lane 2, positive control (DNA extracted from C. cayetanensis used as a template); Lane 3, negative control; Lanes 4-11, patient stool samples.

C. cavetanensis isolate blackberry (MK332313.1)

C. cayetanensis isolate Human (KJ569534.1)

C. cayetanensis isolate Human (KX618190.1)

C. cayetanensis isolate Human (KY770759.1)

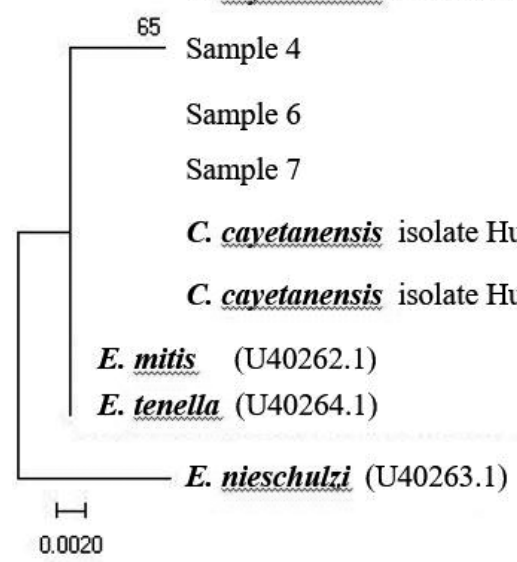

Fig. 2. Phylogenetic analysis of the nucleotide sequences of the bands produced from the patients' stool samples (samples 4,6,7). GenBank accession number U40261, AF111183 was from Nepal; C., Cyclospora; E., Eimeria.

detectable [14]. In the present case, the period from occurring clinical symptoms to collecting time of stool samples took about 30 days. Oocysts can intermittently or continuously continue to be shed by non-symptomatic people, and symptoms can also persist in the absence of oocysts in faeces [22]. Thus the reason for the undetectable oocysts in the stool samples may be that they got over illness and clinical symptoms of most of the affected them had disappeared at the time of sample collection.

The prevalence of traveler's diarrhea of unknown cause among individuals visiting Asia is estimated at 10-56\% [1]. Especially, traveler's diarrhea was the most common clinical symptoms during travel or on arrival and ongoing symptoms were showed by $25 \%$ of all travelers on return home [23]. Recently, tourism to Southeast Asian countries such as Nepal and Indonesia as well as Latin America has increased in Korea; thus, the incidence of traveler's diarrhea caused by enteric pathogens including C. cayetanensis was possible to be increasing unofficially. Therefore, travelers experiencing continuous diarrhea after returning to home from South and Southeast Asia should consider the possibility that they could have been exposed to enteropathogenic parasites while traveling. In this case, C. cayetanensis infection is believed to be through local food intake. As a result of an epidemiological survey over the phone, it was found that the tour group visited the local church and consumed vegetables, water, and fruits. To prevent such infections, all travelers should maintain high standards of personal hygiene and have attention to eating some kinds of local foods while traveling. In addition, travelers with diarrhea of unknown cause after returning home should be appropriately examined at a healthcare facility and be continuously monitored.

The current case represents the second report of imported cyclosporiasis causing traveler's diarrhea in Korea and the first report of a group infection with C. cayetanensis after visiting Nepal known as endemic country with cyclosporiasis.

\section{ACKNOWLEDGMENT}

This research was supported by grants from the Korea Centers for Disease Control and Prevention (4847-302, 2013). 


\section{CONFLICT OF INTEREST}

We have no conflict of interest related to this work.

\section{REFERENCES}

1. Al-Abri SS, Beeching NJ, Nye FJ. Traveller's diarrhoea. Lancet Infect Dis 2005; 5: 349-360.

2. Chacín-Bonilla L. Epidemiology of Cyclospora cayetanensis: A review focusing in endemic areas. Acta Trop 2010; 115: 181-193.

3. Ross, AG, Olds, GR, Cripps AW, Farrar JJ, McManus DP. Enteropathogens and chronic illness in returning travelers. N Engl J Med 2013; 368: 1817-1825.

4. Almeria S, Cinar HN, Dubey JP. Cyclospora cayetanensis and Cyclosporiasis: An update. Microorganisms 2019; 7: 317.

5. Hall RL, Jones JL, Hurd S, Smith G, Mahon BE, Herwaldt BL. Population-based active surveillance for Cyclospora infectionUnited States, foodborne diseases active surveillance network (FoodNet), 1997-2009. Clin Infect Dis 2012; 54 (suppl): 411417.

6. Greenwood Z, Black J, Weld L, O'Brien D, Leder K, Von Sonnenburg F, Pandey P, Schwartz E, Connor BA, Brown G, Freedman DO, Torresi J. Geosentinel surveillance network. Gastrointestinal infection among international travelers globally. J Travel Med 2008; 15: 221-228.

7. Giangaspero A, Gasser RB. Human cyclosporiasis. Lancet Infect Dis 2019; 19: e226-e236.

8. Nichols GL, Freedman J, Pollock KG, Rumble C, Chalmers RM, Chiodini P, Hawkins G, Alexander CL, Godbole G, Williams C, Kirkbride HA, Hamel M, Hawker JI. Cyclospora infection linked to travel to Mexico, June to September 2015. Euro Surveill 2015; 20.

9. Kozak GK, MacDonald D, Landry L, Farber JM. Foodborne outbreaks in Canada linked to produce: 2001 through 2009. J Food Prot 2013; 76: 173-183.

10. Chiodini PL. A 'new' parasite human infection with Cyclospora cayetanensis. Trans R Soc Trop Med Hyg 1994; 88: 369-371.

11. Paudyal R, Tandukar S, Sherchand O, Amatya J, Sherchand JB. Infection of Cyclospora cayetanensis in children under 15 years of age in Kathmandu valley. Scientific World 2011; 9: 86-89.
12. Owen IL. Parasitic zoonoses in Papua New Guinea. J Helminthol 2005; 1: 1-14.

13. Tram NT, Hoang L, Cam PD, Chung PT, Fyfe MW, Renton JL, Ong CS. Cyclospora spp. in herbs and water samples collected from markets and farms in Hanoi, Vietnam. Trop Med Int Health 2008; 11: $1415-1420$.

14. Blans MC, Ridwan BU, Verweij JJ, Rozenberg-Arska M, Verhoef J. Cyclosporiasis outbreak, Indonesia. Emerg Infect Dis 2005; 9: 1453-1455.

15. Bhandari d, Tandukar S, Parajuli H, Thapa P, Chaudhary P, Shresha D, Shah PK, Sherchan JB, Sherchand JB. Cyclospora infection among school children in Kathmandu, Nepal: prevalence and associated risk factors. Trop Med Health 2015; 43: 211-216.

16. Thapa MD, Rai SK, Lekhak B, Rai KR. Study of parasitic infection among children of Sukumbasi Basti in Kathumandu valley. Nepal Med Coll J 2011; 13: 7-10.

17. Kimura K, Rai SK, Rai G, Insisiengmay S, Kawabata M, Karanis P, Uga S. Study on Cyclospora cayetanensis associated with diarrheal disease in Nepal and Loa PDR. Southeast Asian J Trop Med Public Health 2005; 36: 1371-1376.

18. Sherchand JB, Cross JH, Jimba M, Sherchand S, Shrestha MP. Study of Cyclospora cayetanensis in health care facilities, sewage water and green leafy vegetables in Nepal. Southeast Asian J Trop Med Public Health 1999; 30: 58-63.

19. Yu JR, Sohn WM. A case of human cyclosporiasis causing traveler's diarrhea after visiting Indonesia. J Korean Med Sci 2003; 18: 738-741.

20. Korea Centers for Disease Control and Prevention. 2018 Guideline for Control of Waterborne and Foodborne Diseases. Cheongju, Korea. KCDC. 2018.

21. Zhou Y, Lv B, Wang Q, Jian F, Zhang L, Ning C, Fu K, Wang Y, Qi M, Yao H, Zhao J, Zhang X, Sun Y, Shi K, Arrowood MJ, Xiao L. Prevalence and molecular characterization of Cyclospora cayetanensis, Henan, China. Emerg Infect Dis 2011; 10: 1887-1890.

22. Hoge CW, Echeverria P, Shlim DR, Rajah R, Shear M, Rabold G, Triplett J. Epidemiology of diarrhoeal illness associated with coccidian-like organism among travelers and foreign residents in Nepal. Lancet 1993; 341: 1175-1179.

23. Vilkman K, Pakkanen SH, Lääveri T, Siikamäki H, Kantele A. Traveler's health problems and behavior: prospective study with post-travel follow-up. BMC Infect Dis 2016; 16: 328. 